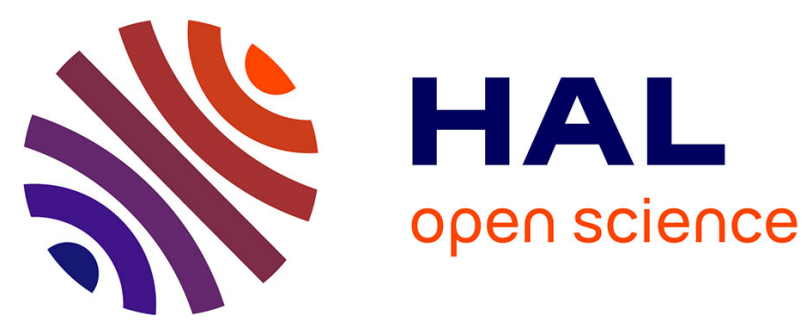

\title{
COLOUR CENTRES IN DOPED ALKALI HALIDES.THE ROLE OF OXYGEN AND TITANIUM IN THE LUMINESCENCE OF LiF : Mg: Ti
}

M. Wintersgill, P. Townsend, F. Cusso-Perez

\section{- To cite this version:}

M. Wintersgill, P. Townsend, F. Cusso-Perez. COLOUR CENTRES IN DOPED ALKALI HALIDES.THE ROLE OF OXYGEN AND TITANIUM IN THE LUMINESCENCE OF LiF : Mg: Ti. Journal de Physique Colloques, 1976, 37 (C7), pp.C7-123-C7-126. 10.1051/jphyscol:1976724 . jpa-00216880

\section{HAL Id: jpa-00216880 https://hal.science/jpa-00216880}

Submitted on 1 Jan 1976

HAL is a multi-disciplinary open access archive for the deposit and dissemination of scientific research documents, whether they are published or not. The documents may come from teaching and research institutions in France or abroad, or from public or private research centers.
L'archive ouverte pluridisciplinaire HAL, est destinée au dépôt et à la diffusion de documents scientifiques de niveau recherche, publiés ou non, émanant des établissements d'enseignement et de recherche français ou étrangers, des laboratoires publics ou privés. 


\author{
THE ROLE OF OXYGEN AND TITANIUM \\ IN THE LUMINESCENCE OF LiF : Mg : Ti
}

\author{
M. C. WINTERSGILL, P. D. TOWNSEND and F. CUSSO-PEREZ (*) \\ School of Mathematical and Physical Sciences, University of Sussex, Falmer, \\ Brighton BN1 9QH, Sussex, Great Britain
}

\begin{abstract}
Résumé. - Dans le matériau LiF : Mg : Ti, utilisé dans les dosimètres commerciaux, la concentration des impuretés est choisie afin d'optimiser la luminescence. On a supposé que la luminescence a lieu par capture d'un trou dans un site de défaut en titane. Cependant la résonance électron-spin a montré que le titane est incorporé au cristal sous la forme d'ions $\mathrm{Ti}^{3+}$ et $\mathrm{Ti}^{4+}$ avec la possibilité d'une compensation de charge par trois ions $\mathrm{O}^{2-}$. Afin de tester cette hypothèse, nous avons mesuré la thermoluminescence d'un grand nombre d'échantillons de LiF avec des variations dans les niveaux de dopage de $\mathrm{Mg}$ et de Ti. L'implantation d'oxygène et de titane a fourni une méthode propre de modification des niveaux d'impureté dans les échantillons. Des changements ont été observés à la fois dans les intensités de thermoluminescence, le nombre de pics de luminescence et dans le spectre de luminescence excité par irradiation $X$. Les résultats sont interprétés en fonction du défaut complexe $\left[\mathrm{Ti}^{4+}, 3 \mathrm{O}^{2-}\right]$.

Abstract. - In commercial dosimeter material $\mathrm{LiF}: \mathrm{Mg}$ : Ti the concentrations of the impurity ions are chosen to optimise the thermoluminescence. It has been assumed that the luminescence occurs by hole capture at a titanium defect site. However electron spin resonance has shown that the titanium is incorporated in the crystal as $\mathrm{Ti}^{3+}$ and $\mathrm{Ti}^{4+}$ ions with the possibility of charge compensation by three $\mathrm{O}^{2-}$ ions. To test this suggestion we have surveyed the thermoluminescence from a wide range of $\mathrm{LiF}$ samples with variations in both $\mathrm{Mg}$ and $\mathrm{Ti}$ doping levels. Ion implantation of oxygen and titanium provided a clean method of modifying the impurity levels in the samples. Changes were observed in both the thermoluminescence intensities and the number of gow peaks and also in the spectrum of X-ray excited luminescence. The results are interpreted in terms of the $\left[\mathrm{Ti}^{4+}, 3 \mathrm{O}^{2-}\right]$ defect complex.
\end{abstract}

1. Introduction. - Lithium fluoride crystals of various purity levels have been the subject of investigation over several decades both as a near approximation to a perfect ionic lattice and as an extremely useful thermoluminescence (TL) dosimeter material. Despite sustained interest, the details of composition of the crystals supplied by manufacturers, and of the mechanisms of TL are remarkably poorly defined. As a first approximation it is now clear that impurities, specifically including magnesium and titanium $[1,2$, $3,4]$ are intimately involved in the TL process whereas it is unlikely that the radiation induced $F$ centre plays more than an incidental role $[2,5]$. Magnesium plus Li-vancancy dipoles either singly or in groups of three (trimers) are now associated with TL trapping sites $[4,6]$ whilst some form of titanium centre has been identified with the luminescence site $[7,8,9$, $10,11]$ so that electron release from $\mathrm{Mg}$ traps eventually leads to hole capture and luminescence at $\mathrm{Ti}$ sites [12].

The possibility that oxygen may be a constituent of the luminescence centre has occurred a number of times $[8,9,10,13]$ and Davies [14] gives a firm suggestion on the basis of his ESR studies that the $\mathrm{Ti}^{3+}$ component of the centre is stabilised by three $\mathrm{O}_{2}^{-}$

(*) Permanent Address; Optica y Estructura de la Materia C-IV, Universidad Autonoma de Madrid, Cantoblanco. ions in nearest neighbour positions. Not only would this structure be consistent with the negative ion EPR interaction observed but would also explain the observation that the $\mathrm{Ti}^{3+}$ is displaced $\sim 0.02 \mathrm{~nm}$ from a normal lattice site.

Previously, the degree to which oxygen occurs in $\mathrm{LiF}: \mathrm{Mg}: \mathrm{Ti}$ and hence its importance in the $\mathrm{TL}$ process has been difficult to quantify. Because of its nuclear structure it lacks an ESR signal so that a potentially very sensitive detection procedure is unavailable in this case. In addition it is extremely difficult to detect by normal mass spectrographic analysis. However, Rolfe et al. [15] and Kanzig and Cohen [16] studied the paramagnetic resonance signal of the $\mathrm{O}_{2}^{-}$molecule in various alkali halides (not $\mathrm{LiF}$ ) and found that it occupied an anion site, with the bond axis along the [110] direction. These studies also give an indication of the ease with which oxygen may be introduced into alkali halides since their method of crystal preparation consisted in heating the samples in air or oxygen.

In order to provide a range of sample materials, six boules with equal titanium doping but a range of magnesium levels were grown simultaneously in a dry nitrogen atmosphere. While the magnesium is evenly distributed throughout the crystal, the titanium, hav. ing a segregation coefficient of 1.7, develops a con- 
centration gradient along the boule $[8,9,17]$. This provided an array of crystals with variations in both magnesium and titanium content. To optimise the TL the magnesium is aggregated to the trimer state by heat treatments at $400^{\circ} \mathrm{C}$ and $100^{\circ} \mathrm{C}$. Therefore a problem arises that additional doping by conventional diffusion methods may disturb the kinetics or the equilibrium of the aggregation. Another difficulty is the possible introduction of other impurities or even outdiffusion of impurities during the diffusion process. The obvious alternative is to use ion implantation to cleanly introduce a known dopant without significantly raising the temperature of the specimen. The response of the crystals in glow curve measurements and during $\mathrm{X}$-ray stimulated luminescence was studied to see if the addition of oxygen affected the phenomena in such a way as to suggest that the number of active luminescence centres had been changed. Implantations of other ions were used for control purposes.

2. Experimental details. - The range of samples used consisted of zone refined $\mathrm{BDH}$ Optran $\mathrm{LiF}$ with additional doping levels of $50,100,200$ and $400 \mathrm{ppm} / \mathrm{wt}$. $\mathrm{Mg}$ using BDH Magtran $\mathrm{MgF}_{2}$. The initial titanium content of the crystals varied from $1.5 \mathrm{ppm}$ to $4.2 \mathrm{ppm}$ and an unknown oxygen content. Samples were approximately $1 \mathrm{~mm}$ thick. All implantations utilised a $300 \mathrm{KeV}$ accelerator at beam currents of $\sim 1 \mu \mathrm{A}$ to give a total dose of $\sim 10^{15}$ ions $\mathrm{cm}^{-2}$.

Glow curves were recorded at a linear heating rate of $50^{\circ} \mathrm{C} / \mathrm{min}$-after $2.87 \times 10^{2} \mathrm{Rad}$ beta irradiation from a ${ }^{90} \mathrm{Sr}$ source. The light output was monitored by an EMI $6097 \mathrm{~F}$ p. m. tube with an S11 response and pulse counting techniques were used to improve the signal to noise ratio.

$\mathrm{X}$-ray stimulation occurred at a dose rate of $4.7 \times 10^{3} \mathrm{Rad} / \mathrm{min}$. and the total light output monitored by an EMI 9524B p. m. tube (S11 response) whilst emission spectra were recorded via a Bausch and Lomb monochromator with a bandwidth of $6.6 \mathrm{~nm}$. The signal was detected using an EMI $6256 \mathrm{~A} \mathrm{pm}$ tube with an $\mathrm{S} 13$ response.

The optical absoption spectra of the crystals used to measure the photostimulated emission spectra, were also recorded using a Cary 14 spectrophotometer.

3. Results. - The unimplanted crystals show the expected variation in the number of peaks and glow curve shape with doping levels of magnesium and titanium as reported by various other sources [18, $8,9,10,2]$. Specifically, for low magnesium levels all the glow peaks were reduced in magnitude, particularly peaks 4 and $5\left(180^{\circ}, 210^{\circ} \mathrm{C}\right)$ which are associated with (Mg plus Li-vacancy) dipole aggregates. Low titanium levels, implying insufficient luminescence sites, lead to a suppression of the higher temperature TL peaks.
It was found that if the crystals were exposed to room light between consecutive irradiation and glow curve measurement, the glow curves were not consistent. However, by keeping the crystals in darkness between runs, the curves were reproducible, although they differed slightly from the first glow curve.

The glow curves from the oxygen implanted crystals which had a high initial titanium impurity level tended to show extra high temperature peaks and an enhancement of the high temperature peaks previously observed (Fig. 1). In contrast, crystals which had a
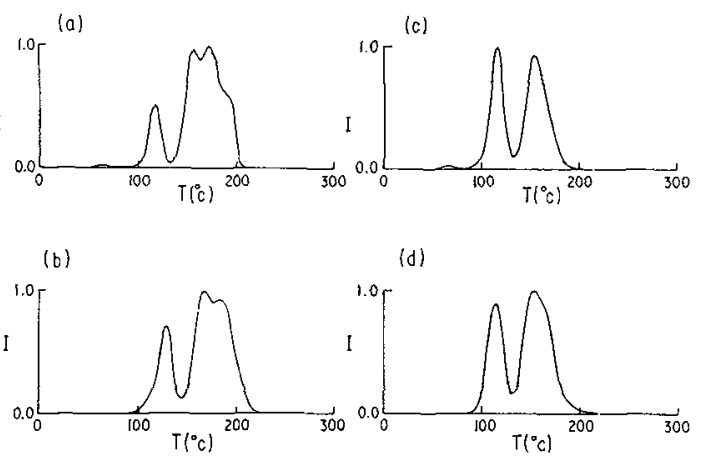

Fig. 1. - TL glow curves measured at $50^{\circ} \mathrm{C} / \mathrm{min}$. : a) $\mathrm{BDH} \mathrm{LiF}+100$ p. p. m. Mg, 4.2 p. p. m. Ti : $1.5 \times 10^{15}$ ions O, $300 \mathrm{keV}$; b) BDH LiF +100 p. p. m. Mg, 4.2 p. p. m. Ti : As grown ; c) BDH $\mathrm{LiF}+100$ p. p. m. Mg, 2.0 p. p. m. Ti : $1.5 \times 10^{15}$ ions $\left.\mathrm{O}, 300 \mathrm{keV} ; d\right) \mathrm{BDH} \mathrm{LiF}+100$ p. p. m. Mg, 2.0 p. p. m., Ti : As grown.

lower initial titanium impurity level showed little or no enhancement of the higher temperature peaks but did so to a small degree when implanted with more titanium (Fig. 2). However these differences were not large or predictable. An implant of $10^{15}$ ions $/ \mathrm{cm}^{2}$ will produce minor changes in the doping levels when averaged over the bulk of the sample $(<0.5$ p. p. m.) but directly after implantation the local change in the surface region is high $(\sim 1000$ p. p. m. under the implant profile).
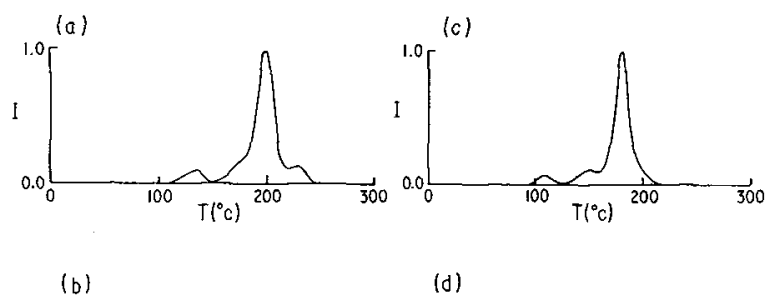

(d)

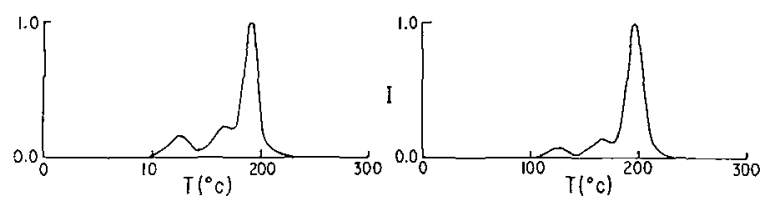

FIG. 2. - TL glow curves measured at $50^{\circ} \mathrm{C} / \mathrm{min} .:$ a) BDH LiF +400 p. p. m. Mg, 1.75 p. p. m. Ti : $10^{15}$ ions Ti, $300 \mathrm{keV}$; b) BDH LiF +400 p. p. m. Mg, 1.75 p. p. m. Ti: As grown ; c) $\mathrm{BDH} \mathrm{LiF}+400$ p. p. m. $\mathrm{Mg}, 3.7$ p. p. m. Ti : $1.5 \times 10^{15}$ ions Ne, $300 \mathrm{keV} ;$ d) $\mathrm{BDH} \mathrm{LiF}+400$ p. p. m. Mg 3.7 p. p. m. $\mathrm{Ti}$ : As grown. 
The irreproducibility between titanium implants may reflect the fact that whilst some ions may diffuse to luminescence sites others may be trapped at nonluminescent centres and indeed it is known that there is an absorption band at $200 \mathrm{~nm}$ which is produced by titanium in conjunction with hydroxyl groups but which is unrelated to the titanium participating in luminescence $[8,2,19]$. Thus the effect of titanium implants were difficult to assess. However, some positive effects were discernible for oxygen implantations. Neon ions which produced radiation damage without the possibility of chemical interaction produced no consistent change in the total light output or the higher temperature TL peaks (Fig. 2).

Different $\mathrm{X}$-ray stimulated spectra were recorded soon after implantation; after $\frac{1}{2}$ hour at $\sim 300^{\circ} \mathrm{C}$ with a cooling rate of $7{ }^{\circ} \mathrm{C} / \mathrm{min}$.; after 1 hour at $350^{\circ} \mathrm{C}$ with slow cooling over 6 hours; and after 1 hour at $400{ }^{\circ} \mathrm{C}$ followed by rapid quench. The X-ray excitations were made with the samples in vacuum and normally anneals were in vacuum but air produced similar results. At room temperature both $320 \mathrm{~nm}$ and $420 \mathrm{~nm}$ emission bands were recorded. Above $130^{\circ} \mathrm{C}$ only the $420 \mathrm{~nm}$ band is apparent. The emission at $420 \mathrm{~nm}$ is associated with the impurity luminescence site which involves titanium, and the $320 \mathrm{~mm}$ emission is considered to result from luminescence involving an intrinsic defect [2]. Examples of these spectra are shown in figure 3.
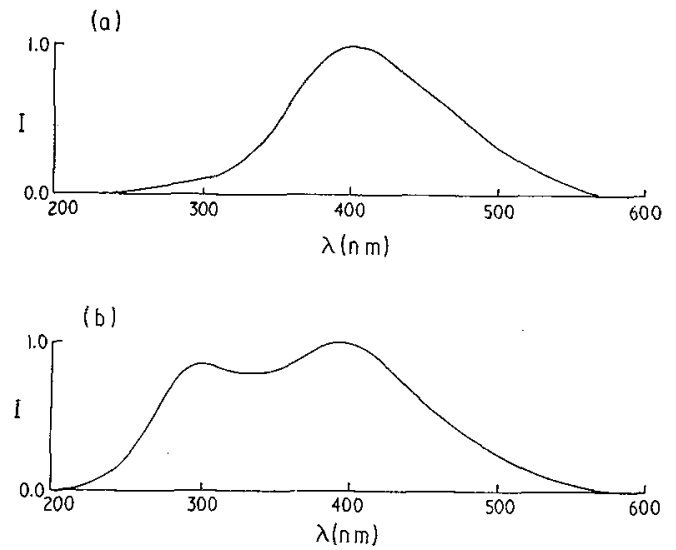

Fig. 3. - X-ray stimulated emission spectra of $\mathbf{L i F}+100$ p. p. $\mathrm{m}$. Mg, 4.2 p. p.m. Ti : a) $290^{\circ} \mathrm{C}$; b) Room Temperature.

The total light output during X-ray stimulation did not show the variation with temperature reported by Gorbics et al. [20] who observed discontinuities at temperatures at which the TL glow peaks occur.

The ratio of the peak heights at $420 \mathrm{~nm}$ and $320 \mathrm{~nm}$ were measured and corrected for variations in the total light out put andfor the p. m. tube response. The relative height of the $420 \mathrm{~nm}$ peak to that of the $320 \mathrm{~nm}$ peak was in general reduced by the first two heat treatments, that is by slow cooling from 300$350^{\circ} \mathrm{C}$. The spectra measured after rapid quenching following 1 hour at $400^{\circ} \mathrm{C}$ showed a marked increase in the peak height ratio $(420 \mathrm{~nm} / 320 \mathrm{~nm})$. This follows the previously observed changes in the state of aggregation with heat treatment and its effect on TL spectral output. The size of the change in peak height ratio varied of course with the initial Ti impurity level and additionally between oxygen implanted and the unimplanted crystals. Damage effects from nitrogen or helium implants did not change the spectra.

For crystals with $\sim 100$ p. p. m. Mg, that is close to dosimeter impurity levels, the change was more pronounced in those with higher $\mathrm{Ti}$ doping levels. In addition the difference in this change between oxygen implanted and unimplanted was most apparent in crystals with high $\mathrm{Ti}$ levels, oxygen tending to increase the variation in peak height ratio. The results are summarised in tables I and II.

\begin{tabular}{|c|c|c|c|c|c|c|}
\hline$\underset{\mathrm{Mg}}{\text { Initial }}$ & $\begin{array}{l}\text { Impurity } \\
\text { ntent } \\
\text { TI }\end{array}$ & Implant & Initiat & ${ }_{2}^{1} \mathrm{hr} 300^{\circ} \mathrm{C}$ & $\begin{array}{l}\text { thest Treatment } \\
350^{\circ} \mathrm{C} \\
\text { slow cooling }\end{array}$ & $\begin{array}{l}\text { I hr } 400^{\circ} \mathrm{C} \\
\text { Quenched }\end{array}$ \\
\hline 100 & 3.7 & 0 & 1,43 & 1.2 & 0.86 & 1.40 \\
\hline 100 & 3.7 & - & 1.22 & 1.08 & 0.88 & 1.59 \\
\hline 100 & 3.25 & 0 & 1.5 & 1.1 & a. 33 & 1.27 \\
\hline 100 & 3.25 & - & 1.3 & 0.9 & 0.93 & 1.2 \\
\hline 100 & 2.0 & 0 & 0.7 & 0.6 & 0.65 & 0.88 \\
\hline 100 & 2.0 & - & 0.88 & 0,99 & 0.83 & 0.92 \\
\hline 50 & 3.2 & o & 0.76 & 0.68 & 0.68 & 0.68 \\
\hline so & 3.7 & - & 0.7 & 0.6 & 0.6 & 0.84 \\
\hline so & 2.44 & $o$ & 1.1 & 0.88 & 0.75 & 1.4 \\
\hline 50 & 2.86 & - & 0.88 & 0.73 & 0.76 & $0.7 n$ \\
\hline so & 1.50 & o & 1.25 & 0.84 & 0.82 & 0.84 \\
\hline$\$ 0$ & 1.50 & - & 1.03 & 0.65 & 0.47 & 1.18 \\
\hline 400 & 4.0 & 0 & 0.68 & 0.52 & 0.59 & 0.66 \\
\hline 400 & 4.0 & - & 0.75 & 0.68 & 0.85 & 0.85 \\
\hline 400 & 3.67 & 0 & 0.73 & 0.64 & 0.56 & 0.75 \\
\hline 400 & 3.67 & - & 0.73 & 0.65 & 0.58 & 0.73 \\
\hline 400 & 1.75 & 0 & 0.64 & 0.60 & 0.60 & 0.78 \\
\hline 400 & 1.75 & - & 0.51 & 0.47 & 0.47 & 0.53 \\
\hline 400 & 3.67 & $\mathrm{~N}$ & $0.7 \mathrm{t}$ & 0.62 & 0.71 & 0.82 \\
\hline 400 & 1.75 & He & 0,42 & 0.52 & e. 53 & 0.69 \\
\hline
\end{tabular}

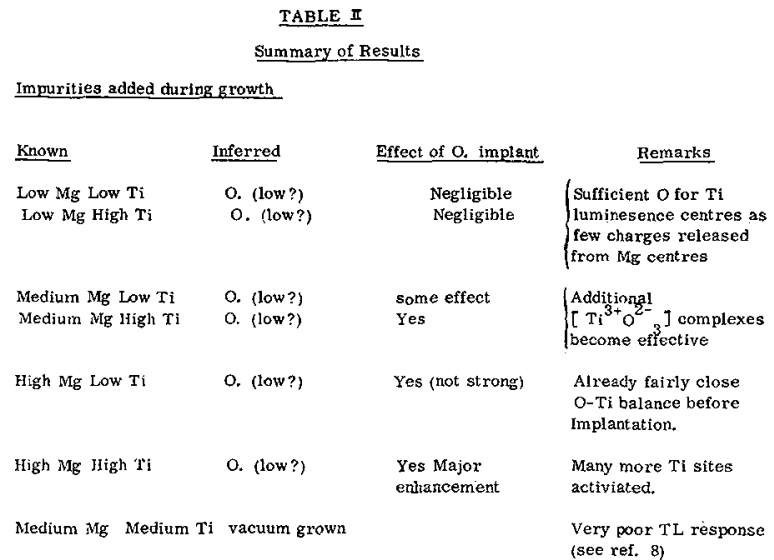

For crystals with a much lower $\mathrm{Mg}$ doping level, these trends although still apparent were much less pronounced. Apart from large F-and M-bands apparent after implantation, which were annealed after the first heat treatment, the optical absorption spectra showed few significant or consistent changes apart 
from the variation in strength of the $F$ band with irradiation.

4. Discussion. - Despite the very small amounts of oxygen implanted into the crystals, $\lesssim 0.5$ p. p. m. averaged over the crystal, some definite changes in glow curve and photostimulated emission spectra were observed. This strongly indicates both the importance of oxygen in the TL process and the efficiency of ion implantation in producing clean accurate doping levels. Previous studies have undoubtedly been hampered by uncertainties in the changes in impurity levels introduced.

The results of the glow curve measurements imply that in crystals with sufficient magnesium trapping centres and a high Ti impurity level, the addition of oxygen increased the number of luminescence sites as evidenced by the increase in intensity of the high temperature glow peaks. This effect was not so obvious in crystals with either low magnesium or low titanium doping levels. Obviously for low magnesium levels, there were already sufficient luminescence sites for the existing traps. The variation with initial titanium level may be explained by considering that whilst titanium has a segregation coefficient of 1.7 and so exhibits a concentration gradient, any oxygen included in the melt will be more evenly distributed along the boule. Hence where high Ti impurity levels occur there would be insufficient oxygen to complete the charge stabilised $\left[\mathrm{Ti}^{3+} \mathrm{O}_{3}^{2-}\right]$ complex whereas at the lowest Ti levels there might well be excess oxygen. Thus the implan- tation of oxygen, whilst ineffective at the low $\mathrm{Ti}$ levels, would allow the potential luminescence sites occurring in the high Ti level crystals to be activated and so increase the total number of luminescence centres.

Similarly for crystals with 100 p.p. m. Mg, the greater magnitude of the change in peak height ratio $(420 \mathrm{~nm} / 320 \mathrm{~nm})$ of the photostimulated emission spectra for high Ti doping, oxygen implanted crystals is due to the increase in the total number of luminescence sites. This increase not only produces more total light but increases the proportion of magnesium traps whose state of aggregation can be monitored.

Again, for crystals with low levels of magnesium but high $\mathrm{Ti}$ levels there are already enough luminescence centres to respond to all the charges released from the trapping centres. Hence at these impurity levels the implantation of oxygen is ineffective. Even if the $\mathrm{Ti}$ concentration is low, the rate of charge detrapping may still not cause a reduction in the efficiency of the phosphor because of a shortage of recombination sites as the oxygen included during the growth may be sufficient to activate all the existing titanium. Further oxygen implantation thus has a negligible effect, in contrast with the conditions of high $\mathrm{Mg}$ concentration when implantation optimises the number of active titanium sites.

Acknowledgments. - We gratefully acknowledge the financial support of the Science Research Council and the British Council.

\section{References}

[1] British Patent No. 1, 059, 518 (1967).

[2] Crittenden, G. C., Townsend, P. D., Gimkes, J., WinTERSGILL, M. C., J. Phys. D 7 (1974) 2410.

[3] Crittenden, G. C., D. Phil thesis, University of Sussex (1973).

[4] Dryden, J. S., Shuter, B., J. Phys. D 6 (1973) 123.

[5] Miller, L. D., Bube, R. H., J. Appl. Phys. 41 (1970) 3687.

[6] Hartmanova, M., Phys. Status Solidi (a) 7 (1971) 303.

[7] Bloch, P., 2nd Int. Conf. on Lam. Dos., Tennessee, U.S. A. (1968) 317.

[8] Rossiter, M. J., Rees-Evans, D. B., Ellis, S. C., GrifFITHS, J. M., J. Phys. D 4 (1971) 1245.

[9] Rossiter, M. J., Rees-Evans, D. B., Ellis, S. C., Proc. 3rd Int. conf. on Lum. Dos., Risø, Roskilde, Denmark, 1971 Rep. 249, p. 1002.

[10] Rossiter, M. J., Rees-Evans, D. B., Ellis, S. C., J. Phys. D 3 (1970) 1816.
[11] Zimmerman, D. W., Jones, D. E., Appl. Phys. Lett. 10 (1967) 82.

[12] MaYhugh, M. R., J. Appl. Phys. 41 (1970) 4776.

[13] Klick, C. C., ClafFy, E. W., Gorbics, S. G., Attix, F. H., Schulman, J. H., Allard, J. G., J. Appl. Phys. 38 (1967) 3867.

[14] Davies, J. J., J. Phys. C 7 (1974) 599.

[15] Rolfe, J., LipPSet, F. R., King, W. J., Phys. Rev. 123 (1961) 447.

[16] Kanzig, W., Cohen, M. H., Phys. Rev. Lett. 3 (1959) 509.

[17] Pfann, W. G., Trans. Am. Inst. Min. Metall. Pet. Eng. 194 (1952) 747.

[18] Townsend, P. D., Proc. Br. Ceram. Soc. 9 (1967) 125.

[19] Vora, H., Jones, J. H., Stoebe, T. G., J. Appl. Phys. 46 (1975) 71.

[20] Gorbics, S. G., Nash, A. E., Attix, F. H., Proc. 2nd Int. Conf. on Lum. Dos. Tennessee, U. S. A. (1968) 568

\section{DISCUSSION}

R. NINK. - What is the thickness of the surface layer influenced by ion implantation in comparison to the thickness of the crystal ? Is the surface layer thickness good enough for making measurable effects ?

M. C. WintersGiLl. - The crystals are typically $1 \mathrm{~mm}$ thick and whilst under the implant profile the oxygen concentration is high, under the action of the heat treatments, the oxygen diffuses and, averaged over the bulk of the crystal, results in changes of only 0.5 p. p. m. This indicates the efficiency of ion implantation in introducing a single known impurity and also the importance of oxygen, in producing effects even at very small changes in impurity levels. 